\title{
CUSTOMER RELATIONSHIP MANAGEMENT SYSTEMS (CRM) AND INFORMATION ETHICS IN CALL CENTRES - 'YOU ARE THE WEAKEST LINK. GOODBYE!'
}

\author{
Helen Richandson? \\ Information Systems Research Centre, \\ University of Salford. \\ M5 4WT \\ UK \\ H.Richardson@salford.ac.uk \\ And \\ Kate Richardson \\ Manchester Metropolitan University \\ Oxford Road \\ Manchester
}

\begin{abstract}
This paper catalogues the rise and rise of call centres in the North West of England, UK and their use of CRM systems. CRM systems often imply new technologies and new ways of working. However, in this account we explore the historical development of the telegraph and work in early telephone exchanges and find the same old story. Our consideration of the ethics of CRM system use and some inherent contradictions are in terms of privacy, communication richness, management methods and computer ethics in an organizational context. Call centres today are viewed by some as offering satisfying employment of intrinsic value, for others, they are the 'new sweatshops of the $21^{\text {If }}$ century' (Belt et al 2000). Our interpretative field study makes a contribution to this debate.
\end{abstract}

Keywords: CRM, information ethics, call centres, scripts.

\section{INTRODUCTION}

We are said to be living in a new economy, a virtual age where information is power and strategic use of Information Technology (IT) paramount. Electronic media can enable organizations to deliver products and services more efficiently and effectively allowing for competitive advantage through internal networks and external customer management (Loebbecke 1998). In this context CRM is the new buzz phrase. CRM systems are about 'allowing organizations to do a better job in contacting customers, caring for them and providing quality, service and value' (Yourdon 2000). CRM is increasingly about use of call centres and Datamonitor predicts that the global call centre software market will reach $£ 5.3 \mathrm{bn}$ by 2003 (FT 2000). CRM is not without it's critics. It is popular for those 'managing' customers but can stimulate different emotions if you are the 'managed'. 'Where is the R in CRM - it's all about customer management' (Professor Stone in FT 2000). There are startling contrasts in the image of CRM in call centres. For the consultants and employers, CRM use in call centres means knowledge intensive, strategic use of technology, flexible working and utility of all those new ways of working like flattened organizations, teamwork and empowerment. For others, they are the 'sweatshops of the $21^{\text {st }}$ century' (Belt et al 2000).

Our study is about call centres in the NW of England. Ironically these are often housed in the old mills and engineering shops once foremost in the industrial revolution but long since idle. That is until the 'virtual' age and we consider whether this is indeed the new economic era, or history repeating itself. Call centre work is characterised by temporary, short-term contracts, agency working and casual employment. Nevertheless, we have shadowed 4 call centre workers over a period of 2 years. We have documented their tales of stress, burn out, sacking, job changes and frustration but also the community, solidarity and collective action that suggest a more rosy future than the "dark satanic call centre mills'10 seems to offer. The ethical issues we raise lie in the inherent contradiction of CRM systems and their use in call centres.

The paper shall proceed as follows. Firstly, we look at the technologies and the new ways of working implied. Then we consider the inherent contradictions in CRM systems. Next we introduce our interpretative field study based on workers in a number of different call centres in the North West of England, UK. We conclude by offering two future scenarios of CRM system use in call centres, one supporting the 'dark satanic mills' image and one a more ethically robust picture.

\section{CRM SYSTEMS AND CALL CENTRES}

Telephone call centres are specialist technology-intensive offices that deliver services to customers over the telephone, replacing or complementing face-to-face interaction with the public (Richardson 1994). This front line work is vital and significant to an organization. It is often strategically important work. It is rarely

\footnotetext{
${ }^{9}$ To whom correspondence should be addressed

${ }^{10}$ part of a poem by William Blake, now a famous hymn called 'Jerusalem'
} 
completely routinized with a need to tailor to customer requirements and be sensitive to business changes. Workers are 'on-stage' undertaking tasks that involve emotional labour. So front line workers need to be emotionally resilient and flexible, there are no buffers to protect workers from the inevitable 'spikes' of dealing with customers (Frenkel et al 1999). CRM system use is aimed at streamlining and shortening the key business processes that define a global organization's relationship to the markets and customers. CRM is not a technology but a strategic business issue that requires technology support (Ciborra 2000). However a number of IT tools can be utilised e.g. automated call distribution systems (ACD) using computer telephony integration in order to retrieve customer records. They can use voice recognition and response software to get initial information from the customer, integrated volume response and automated response, use of the World Wide Web and speech recognition. These may all further decrease the need for high value agents (Frenkel et al 1999). A most highly treasured aspect of CRM system use though is the opportunities afforded for electronic performance monitoring. Access is gained to employee's terminals and headsets and all aspects of work, worker or team performance can be monitored and workflow measured.

From a customer-relations point of view however, Gutek (1995) has questioned how deep the relationships are. They are more like 'customer encounters'. Our research confirms this with call time strictly monitored and pressure for quick 'closure'. We consider the inherent contradictions between CRM systems and the strategically important front line work in terms of privacy, communication richness, management methods and computer ethics in an organizational context.

\section{Privacy}

Even for managers, CRM raises questions of privacy with IT 'strategic guerrilla's' locking in systems and knowledge, of others in the value chain. For call centre workers, issues of privacy are tied up with work practices. Headsets are worn with call after call streaming in - always another one waiting. CRM systems means codifying intellectual capital (Light 2001) with software providing 'scripts' enabling monitoring and call analysis. This metaphorically, if not physically, welds the worker and machine into a streamlined and controlled knowledge system. No aspect of a call centre workers day is unaccounted for. They are profiled, listened in to, their opening remarks are analysed as are wrap-up time and phrases used. The sales content of their conversations, achievement of call numbers and sales targets scrutinised. Their off-line frequency, intimate toilet habits are considered and discussed at teamwork supervision sessions as are perceived attitudes displayed during conversations with customers. Scripts are a technique to analyse the social construction of the user of Information Systems (IS) and a means to look at the constraints of free action (Akrich 1992). Even commonsense knowledge, in these terms, is classified and assigned. In our everyday world, the common reasons that we might consult a call centre or respond as a worker in a call centre is organized by a 'predetermined, stereotyped sequence of actions that define a well-known situation or script' (Schank and Abelson 1977). Architects of CRM systems, for example, want to 'predict the future world of the user and the machine' but Wilson and Howcroft (2000) stress the important focus of contradiction and resistance, always apparent and possible with humancomputer system interaction in an organizational context. In these terms we note the imperative to formalize, standardize and rationalize with the use of scripts and CRM systems in call centres. However we also identify resistance from non-compliant users actively or otherwise failing to act out the 'script'. Intense monitoring in the process of the control of machine and user is not confined to the introduction of CRM systems however. Julia O'Connor, the President of the Telephone Operators Department of the International Brotherhood of Electrical Workers noted in 1920 'headset tests on an operator's position have neither morale nor service justification...this person constantly on the job to discover your faults... is one of the meanest elements' (Norwood $1990 \mathrm{p} 39$ ).

\section{Communication Richness}

CRM rhetoric emphasises quality customer care and how this is related to effective communication. This is particularly by the gatekeepers - a role delivered by call centre workers. We contend that a consideration of communication richness in an organizational context is important, that goes beyond considering Information Communication Technologies merely as information transferors and processors, but constitute new statuses and formation of new identities (Flores 1998). It is difficult to associate genuine identities in the components of virtual communities in a global business world. Flores (1998) notes that our identities are vexed because all the terms with which they are given us are in the control of the community through various agencies. Whether cost efficiency or customer satisfaction is esteemed and so on, all these choices affect how our personal identities are evaluated. In terms of customer relations 'one moment partnerships with customers are championed...the next...we read about the sad shape of companies that went too far in their partnership arrangements and had their profit margins crushed' (Flores $1998 \mathrm{p} 354$ ). In terms of call centre work the front line worker is a 'sacrifice of oneself (Mills 1951). Moreover using the controlled phrases or scripts that CRM systems demand can be likened to working in the New York telephone exchanges in the early $20^{\text {th }}$ century. 'You had to ask permission to 
use anything but the set phrases. As a result the operator seemed 'strangely impersonal...an automaton, wound up always to say the same things over and over again' (Norwood 1990 p36). Our research implies the same old story. Others have suggested that 'good' management should adopt rich media (Ngwenyama and Lee 1997) and how limiting electronic media is in its richness. Nevertheless our research reveals how call centre staff circumvent the scripts and controlled phrases and rich human communication and problem solving makes the job more satisfying. This is despite facing frequent and sustained verbal abuse from customers.

\section{Management methods}

CRM system use in call centres goes hand in hand with the adoption of teamwork and empowerment management methods. Again contradictions are evident with CRM systems designed to dis-empower sales staff encoding their customer knowledge and so on (Light 2001). Our research showed how sales roles, for example, were increasingly regimented, with initiative, discretion and enterprise removed as far as possible.

To start the process of ethical decision making, some have suggested that 'when it comes to virtual organizations, we must first have a set of commonly accepted values and norms' (Gotterbarn 1999). We look at the realities of using teamwork and empowerment techniques in call centres and suggest that the gap is too wide between call centre workers and management for this to be achieved. The remoteness of management control through the IT tools may seem like technology is controlling rather than it being a human activity. It has to be noted however that there are indeed choices in management methods. Teamwork sessions in our study included dissemination of orders from the top down and attempts to exert team pressure on the 'weakest link'. Often these measures backfired with general community solidarity of call centre workers overriding team identity. Furthermore, this is not a new way of working but these practices are part of the process and imperative of capital accumulation. Mumford (1999) in a critique of Business Process Re-engineering talks about the 'pressures for rapid gains in productivity without concern for employee gains'. Moreover, IS Departments need to 'justify their overall profitability in the face of threats to outsource and also doubts about the financial returns from investment in IT' (Robinson and Richardson 1999). The development and use of CRM systems in call centres needs to be seen in this context.

\section{Computer Ethics in an organizational context}

Ethical issues of workplace privacy generally centre around concepts of personal autonomy and dignity infringed by these practices, yet some would suggest workplace privacy should extend further, worthy of becoming a matter of organizational justice (Introna 1999). It is relevant here to look at the contradictions of call centres and CRM systems. They are exploitative and work against communication richness. They increase bureaucracy yet supposedly embrace empowerment. They are about control of communication and yet to provide quality to customers, need to enhance the "company ambassadorial" role of call centre workers (Frenkel et al 1999). Computer ethics and its adherence to technological determinism and liberalism are problematic for understanding issues of equality and participation (Adam 1999), and moreover power structures play a large part in the making and accepting of knowledge (Adam and Richardson 2001). In this context it is our contention that a debate on the ethical issues of CRM systems, information management and call centres is long overdue.

\section{OUR FIELD STUDY}

Our area of study has the largest number of call centre jobs in the UK- over 72,000 . Pay is $59 \%$ of average UK eamings with the mid-point average being $£ 12,000$ a year (TUC 2001). There are many types of call centres. These include dotcoms and public service centres e.g. help desks. They can involve business to business intranets with internal distribution of jobs or outsourced services e.g. free phone lines offering multi organization services. They can be portal models that rely on attracting maximum users to a web site to drive advertising, negotiate bulk purchasing deals or charge $3^{\text {rd }}$ parties to access customers.

\section{Research Methods}

Our research rather than taking a company or case study model representing examples from each call centre type, instead aimed to follow the fortunes of 4 call centre workers over 2 years as an interpretative and 'mobile' field study. We held focus group sessions and conducted in-depth individual interviews. Here we show life on the front line, present some stories and conclude on contrasting futures. 


\section{Life on the 'front line'}

'Telephone operating was always low paying and became an increasingly regimented and alienating form of labor' (Norwood 1990 p6). Far from a contemporary observance, this statement refers to the early $20^{\text {th }}$ century. Our research reveals the same old story. Blauner (1964) has identified several individual task related freedoms that together comprise control over the immediate work process, namely control over the pace of work, freedom from pressure, freedom of physical movement and ability to control the quantity and quality of production and techniques of work. When technology and work organization do not permit active intervention in these areas then the alienating tendencies of modern industry that makes the worker 'a responding object, an instrument of the production process, are carried to their furthest extremes' (Norwood 1990 p63). Such is the experience of alienation facing the call centre workers in our study. We have chosen names from a UK pop group S Club 7 to conceal the identities of our interviewees.

\section{Hannah's story}

The average length of time spent working in a call centre is 18 months (FT Feb. 20 2001). Hannah is an exception to this. In her late 40's, Hannah has been working in call centres for nearly 10 years. Most of this has been for a telecommunications organization in her hometown. She became an example of a highly valued agent, with intensive knowledge of the area and customers (Frenkel et al 1999) and could give a highly personalized and rich service. Redundancy followed as the organization transferred to a large, impersonal and centralized service utilizing CRM systems to the full. Later Hannah joined this call centre as an agency worker. She was alarmed at the change in working conditions finding teamwork and supervision intimidating and the work pressurized and impersonal. There is a myth that CRM brings about greater speed and efficiency of work. Hannah's case belies this. In her previous job with the firm, Hannah could give out 5 numbers to customers and on average her calls lasted 15 seconds. In the new call centre, customers were only permitted 2 numbers per call and the average length of call is 30 seconds.

Hannah reported that calls were dissected into 4 parts. \#1 a welcome and introduction; \#2 offering products and services; \#3 recap call; \#4 positive close. Imposing exact phraseology in terms of 'scripts' on the workers enables greater monitoring and analysis by CRM systems. Hannah faced difficulties with management for failing to use the exact words "and to recap". Supervisors made Hannah put labels on her monitor with the words on and she had to tick a 'star chart' when she used the words. This is a technique also used by psychologists for behaviour modification in young children. Her calls were monitored closely and listened in to. Saturdays were colloquially called the 'sacking day'. It was easier and less obvious for management to dismiss someone on a Saturday. One Saturday, Hannah was sacked for again using words similar to, but not actually "and to recap".

\section{Bradley}

To contrast Hannah, an experienced call centre worker with a long history of this type of employment, Bradley is a young, gay man who is a 'DJ' at night and dreams of travel and going back to college. Bradley works from call centre agencies but is intolerant of bullying and intimidation from management. If he doesn't like the work or atmosphere, he walks down the road to the next call centre. Hence in 18 months of our 'shadowing', Bradley's call centre experience was as follows: Large telecommunications firm -1 year; financial sector -3 months; telecommunications services -2 months; retail catalogue -6 weeks; ticket sales -3 weeks; credit card company - 1 day. He mainly disliked abusive customers and the constant remote monitoring and listening in. Bradley's comments on privacy: 'you can't be early, can't be late, can't go for a sh*t'.

\section{John}

John is in his early 40's and was a supervisor. He was trying hard to build up experience to become a manager but despite this was supportive to staff, 'he drove me home when I freaked one day' said Jo. He had respect from colleagues. One day his line manager told him 'you're alright for a queer'. John said 'call me a $\mathrm{f}^{* * *}$ ing queer again and I'll punch your lights out.' Management tried to discipline him, but support from the staff meant they failed.

Jo is in her 30's and during the months of this study, worked in two call centres dealing with the public and distributing work to engineers. Jo also studied part-time for a postgraduate diploma in Business and IT and would get annoyed with the 'management clap-trap' on the course that was hot on IT strategy for competitive advantage but cool on understanding the realities for low paid call centre workers. After 18 months, Jo suffered 
stress and burn-out driven by the ACD systems, lack of control, remote listening, abusive customers and low pay. 'I hated being happy, happy, happy all the time - the voice with a smile'. Call centre workers today often face periods when they can't stop crying and exhibit other symptoms of stress. Jo remembers with amusement all the statistics that were kept and all the codes they had to use, 'there was even a code for running to the restroom in tears because of stress'. Jo loved the part of the job that involved dealing with people and sorting problems out. Despite the scripts and regulated phraseology, Jo would refer customers to appropriate agencies that could help with debt and so on. One distressed customer had recently fallen downstairs but was dealing with an upsetting letter relating to her telephone being cut off. As is necessary with customer service occupations, in contradiction to increasing regulation of all aspects of the work that CRM systems demand, workers also have to have discretion and freedom to act at times. Workers cannot be completely manipulated to adhere to configured scripts. Jo stopped the process that should have resulted in cutting the phone line of the customer and instead rang a relative and ambulance. For this she gained a company 'heroism' award.

\section{Community and Solidarity}

A recent Trades Union Congress (TUC) report catalogues problems in call centres (TUC 2001). These included workers victimised if they join a union, lack of toilet and other breaks, increased health problems of 'acoustic shock' that are freak sound bursts on telephone headsets, leaving victims in severe pain with loss of short term memory. Our stories were not all grim however. A lot of solidarity and community feeling arose among the call centre workers in our study. Someone was burgled and they had a collection to replace items. Cakes were baked for birthdays. One bonus for surpassing sales levels was the issuing of supermarket vouchers. Bradley won $£ 400$ worth of vouchers in a national sales competition, although he admitted privately that this had been achieved by adding items to customer bills and waiting for complaints later! If workers were hard up for cash, these vouchers were exchanged for a cash value and on this basis Bradley managed to buy a plane ticket to Jamaica. Management methods often intimidated, yet solidarity helped in many cases. In one team, a number moved from agency work to permanent contracts but management wanted to impose poorer working conditions. The whole team took off their headsets and refused to work. In a short time, old conditions were restored. Workers would 'look out' for each other. Workers would use 'non-verbal communication' to indicate to others that they were dealing with an abusive customer or difficult call. Friends would then also listen in to the call to give help and solidarity and lessen the stress. This showing of solidarity is again not confined to call centre work in the $21^{\text {st }}$ century. Tom Standage has written about the development of the 'Victorian Intemet' namely the telegraph system in the $19^{\text {th }}$ century: 'During quiet periods on-line interaction really got going with stories, gossip, jokes etc circulating along the wires. On one occasion an out-of-hours meeting was held between Boston and Maine attended by hundreds of operators in 33 offices along 700 miles. Each speaker tapped out their views in Morse code and all the offices received the remarks at the same time "annihilating space and time and bringing together the different parties.....as though they were in the same room" (Standage 1998 p125).

During the time of our study, there was a major official strike against bullying in one of the organizations. This precipitated the TUC and call centre organizations to consider good practice and a more ethical future (TUC 2001).

\section{CALL CENTRES - ALTERNATIVE FUTURES}

Frenkel et al (1999) identifies two contrasting images of call centres work. Workers are regimented, routinized, and viewed as replaceable resources. Constant surveillance, high performance standards, programmed learning and strict discipline is the norm. It is emotional labour with inadequate compensation. It is coercive and enervating work. Alternatively, the work is intrinsically rewarding and Human Resources Departments provides skill and knowledge enhancing competencies that help develop employee's careers. The work is enabling, competency enhancing and socially satisfying. Tendencies in service work suggest that the work will become more complex, more product variety will lead to policy and procedural changes so there will be a need for better access to information and conversion to useable knowledge. Greater emphasis on sales will require better social skills. 'Smart technology ...could result in the realisation of the empowered front line workforce' (Frenkel et al p272).

The other response could be that service work is outsourced and 'dumbed down' with a low knowledge, low skill strategy pursued. Reliance on technology in this scenario will lead to increased standardisation. This suggests increasing atomisation and high labour turnover (Frenkel et al 1999). Indeed labour turnover today is a problem. Organizations publicly admit to $20 / 30 \%$ but privately admit it's double that figure (TUC 2001).

The TUC suggest best and ethical practice is unionised workplaces, allowing for flexibility to fit in with family lives and zero tolerance of harassment and bullying. There should be training programmes and skill development indicating valuing of employees. Which is the future scenario? Let's leave the last words to Hannah who adamantly exclaimed 'I'll never work in a call centre again'. 


\section{REFERENCES}

Adam, A. (1999) Computer Ethics in a different voice. in The Proceedings of the $\mathbf{1}^{\text {st }}$ Critical Management Conference. Manchester July 1999

Adam, A., Richardson, H. (2001) “Feminist Philosophy and Information Systems." Information Systems Frontiers, 3 (2)

Akrich M (1992)The de-scription of technical objects in: Bijker W.E. and Law J. (eds) Shaping Technology/Building Society MIT Press

Belt, V., Richardson R., Webster, J. (2000) "Women's work in the Information Economy: the case of telephone call centres." Information Communication and Society 3:3 2000

Blauner, R. (1964) Alienation and Freedom. cited in Norwood, S.H. (1990) Labor's Flaming Youth Telephone Operators and Worker Militancy 1878-1923. University of Illinois Press. 1990

Ciborra, C. U. and Associates (eds) (2000) From control to drift. The dynamics of Corporate Information Infrastructures. Oxford University Press.

FT. (2000) Understanding CRM. FT Financial Times. Spring 2000 www.ft.com $/ \mathrm{crm} /$

Flores, F. (1998) "Information Technology and the institution of identity." Information Technology and People Vol. 11 no 41998

Frenkel, S., Korczynski, M., Shire, K., Tam, M. (1999) On the Front Line: Organization of Work in the Information Economy. (Comel University Press)

Gutek, B.A. (1995) The Dynamics of Service cited in Frenkel, S., Korczynski, M., Shire, K., Tam, M. (1999) On the Front Line: Organization of Work in the Information Economy. (Cornel University Press)

Gotterbarn, D. (1999) An ethical decision support tool in The proceedings of the $4^{\text {th }}$ ETHICOMP conference 1999

Introna, L. (1999) Privacy, autonomy and workplace surveillance in The proceedings of the $4^{\text {th }}$ ETHICOMP conference 1999

Light, B. (2001) A Review of the Issues Associated with Customer Relationship Management Systems in The Proceedings of the $9^{\text {th }}$ European Conference On Information Systems, 27-29 June, Bled, Slovenia. 2001.

Loebbecke, C. (1998) Economics of content provision on the Internet in The proceedings of the $8^{\text {th }}$ Annual BIT conference. Manchester November 1999

Mills, C. W. (1951) White Collar. cited in Frenkel, S., Korczynski, M., Shire, K., Tam, M. (1999) On the Front Line: Organization of Work in the Information Economy. (Cornel University Press)

Mumford, E (1999) Routinisation, Re-engineering and Socio-Technical Design: Changing Ideas on the Organisation of Work in Currie, W.L and Galliers B. (eds) Rethinking Management Information Systems Oxford University Press

Ngwenyama, O.K., and Lee, A.S, (1997) "Communication richness in e-mail” MISQ Vol. 21 No 2 June 1997

Norwood, S.H. (1990) Labor's Flaming Youth - Telephone Operators and Worker Militancy 1878-1923. University of Illinois Press. 1990

Robinson B., Richardson H. (1999) The Crisis of the Information System Discipline: a Vygotskyan Analysis in The Proceedings of the $1^{\text {st }}$ Critical Management Conference. Manchester July 1999

Schank,R., Abelson R. (1977) Scripts, Plans and Knowledge in Johnson-Laird P., Wason P. (eds) Thinking: Readings in Cognitive Science Cambridge University Press cited in Suchman L.A. (1987) Plans and Situated Actions The Problem of Human machine Communication Cambridge University Press.

Standage, T. (1998) The Victorian Internet Weidenfield and Nicholson

TUC (2001) It's your call. TUC call centre workers campaign. Trades Union Congress. February 2001

Wilson M., Howcroft D. (2000) The Role of Gender in User Resistance and IS Failure in Baskerville R., Stage J., and DeGross J. (eds) Organizational and Social Perspectives on Information Technology, Kluwer Academic Publishers, Boston, Mass, 453-472

Yourdon, E. (2000) "Introduction to the special issue on CRM." Cutter Journal Vol. 13 No 10 October 2000 